\title{
НОВЫЕ ОПОРНЫЕ
}

\section{ПОМЕХОПОДАВЛЯЮЩИЕ}

\section{КЕРАМИЧЕСКИЕ КОНДЕНСАТОРЫ}

\author{
В.Смирнов, к.т.н.. ${ }^{1}$ А.Шалаева ${ }^{2}$, А. Харитонов ${ }^{3}$
}

УДК 621.38

BAK 05.27.00

\author{
АО "НИИ "Гириконд", входящее в состав холдинга "Российская \\ электроника",- базовое предприятие радиоэлектронного \\ комплекса России в области конденсаторов и нелинейных \\ полупроводниковых резисторов. Институт является ведущим \\ разработчиком помехоподавляющих фильтров и конденсаторов. \\ Здесь разрабатываются и производятся электронные компоненты, \\ датчики и приборы как универсального применения, так \\ и уникальные изделия для специфических и экстремальных условий \\ эксплуатации (для СВЧ-диапазона частот, работы при повышенных \\ температурах и механических нагрузках и др.), а также материалы \\ для них. Новые керамические опорные помехоподавляющие \\ конденсаторы отличаются низкими значениями собственной \\ индуктивности, имеют широкую линейку напряжений $(250,500,750$ \\ и 1000 В) и емкостей (от 4,7 пФ до 0,33 мкФ), резонансная частота \\ составляет от 4,4 до 1100 МГц, значения вносимого затухания \\ достигают 60 дБ.
}

ПОМЕХОПОДАВЛЯЮЩИЕ КОНДЕНСАТОРЫ:

\section{ТРЕБОВАНИЯ И КОНСТРУКЦИИ}

обеспечение помехоустойчивости - одна из основных проблем при проектировании радиоэлектронных устройств. Ее особая актуальность обусловлена широким применением источников вторичного электропитания, которые могут служить генераторами высокочастотных помех. Применение высокоскоростных цифровых устройств также приводит к возрастанию частоты помех. Если раньше требования к максимальной частоте помехоподавления составляли не более 50 МГц, то теперь уве-

\footnotetext{
АО "НИИ "Гириконд", vladfs2014@yandex.ru.

АО "НИИ "Гириконд", 352@giricond.ru.

АО "НИИ "Гириконд", kharitonovbonch@gmail.com.
}

личены до 100 МГц и выше. Наиболее опасными являются кондуктивные помехи, распространяющиеся в проводящих цепях питания, управления, коммутации.

Для устранения таких помех применяются блокировочные конденсаторы, предназначенные для замыкания их на корпус аппаратуры, "землю". Опорными называются помехоподавляющие конденсаторы, в конструкции которых есть опорный вывод, обеспечивающий малую индуктивность соединения одного из электродов конденсатора с корпусом аппаратуры. Опорные конденсаторы отличаются от аналогичных устройств лишь конструкцией и некоторыми дополнительными требованиями к электрическим параметрам (эквивалентному последовательному сопротивлению и частоте помехоподавления). 
Амплитудно-частотная характеристика (АчХ) полного сопротивления (Z) конденсаторов (рис.1) имеет U-образную форму, в левой ветви которой Z уменьшается пропорционально частоте и достигает минимального значения на частоте собственного последовательного резонанса $f_{\text {рез }}$. На этой частоте величины емкостного и индуктивного реактивных сопротивлений одинаковы и противоположны по знаку, а результирующее реактивное сопротивление равно нулю. На частоте собственного последовательного резонанса общий импеданс будет равен эквивалентному последовательному сопротивлению $\left(\mathbf{R}_{\text {эпс }}\right)$. На частотах ниже частоты последовательного резонанса Z определяется емкостью, а выше-индуктивностью, увеличиваясь пропорционально частоте. Для устранения кондуктивных помех их (помехи) по цепям распространения нужно накоротко замкнуть по переменному току на заземленный корпус. Но наличие в цепи конденсаторов активного сопротивления $\mathbf{R}_{\text {эпс }}$ не позволяет этого сделать. По этой причине минимально достижимые значения эквивалентного последовательного сопротивления - одно из главных требований к опорным помехоподавляющим конденсаторам.

Достижение максимальной частоты помехоподавления зависит от значений частоты собственного последовательного резонанса $f_{\text {рез }}$ и собственной индуктивности L, определяемых конструкцией электродов и выводов конденсатора. Для повышения частоты $\mathrm{f}_{\text {рез }}$ необходимо обеспечить минимально возможные значения индуктивности. Для оценки параметра помехоподавления обычно используются термины "ослабление" или "вносимое затухание". В настоящей статье предпочтение отдано второму варианту. Вносимое затухание соответствует ослаблению электрического сигнала переменного тока, вызванному включением конденсатора в электрическую схему.

Значение вносимого затухания (А, дБ) вычисляют по формуле:

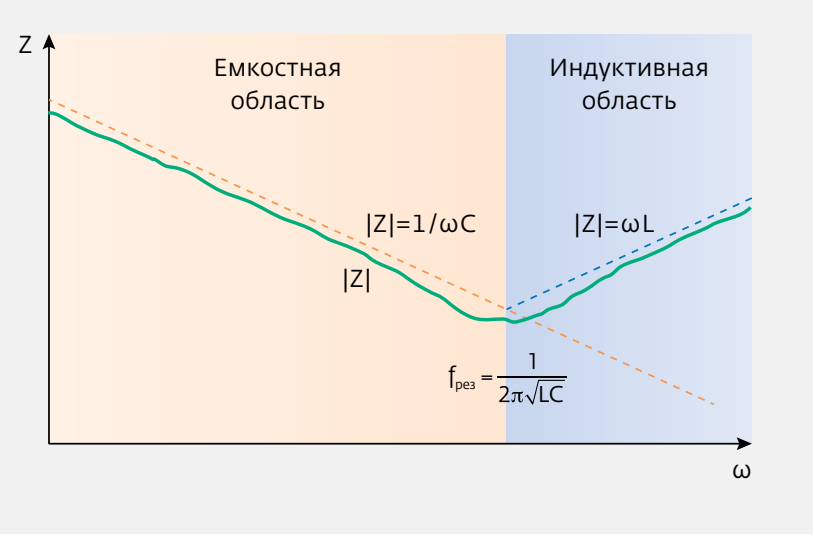

Рис.1. АЧХ опорных конденсаторов

$$
A=20 \lg U_{1} / U_{2}
$$

где $U_{1}$ - напряжение в цепи без конденсатора,

$\mathrm{U}_{2}$ - напряжение с установленным конденсатором.

Разработка помехоподавляющих конденсаторов в НИИ "Гириконд" началась с 1950-х годов. Были созданы дисковые керамические опорные конденсаторы КДО, трубчатые опорные конденсаторы КО, другие опорные конденсаторы с органическим диэлектриком. Конденсаторы КО, КДО до последнего времени выпускались заводом "Номинал" на Украине и использовались на ряде предприятий России. В связи с прекращением поставок встал вопрос об их замещении. Конденсаторы КДО имеют металлический фланец с резьбовой шпилькой (опорный вывод), на котором размещен емкостной элемент в виде однослойного керамического дискового диэлектрика. Максимальная номинальная емкость КДО равняется 2200 пФ. В случае такой емкости нижняя граница диапазона частот помехоподавления, при которой вносимое затухание равняется 3 дБ (частота среза), составляет 2,9 МГц. Максимальная номинальная емкость конденсаторов КО также небольшая-4700 пФ, поэтому они не могут обеспечить эффективное помехоподавление в области низких частот. В этом диапазоне частот с такой задачей справляются опорные конденсаторы с органическим диэлектриком К73-57, однако у них большая собственная индуктивность, ограничивающая помехоподавление в высокочастотной области. На частоте 100 МГц вносимое затухание составляет всего 10 дБ (рис.2).

В конце 1950-х - начале 1960-х годов в конструкциях и технологии изготовления керамических конденсаторов произошли принципиальные изменения. Были разработаны методы литья тонких керамических пленок, с применением которых создан новый тип керамических конденсаторов - многослойные. Максималь-

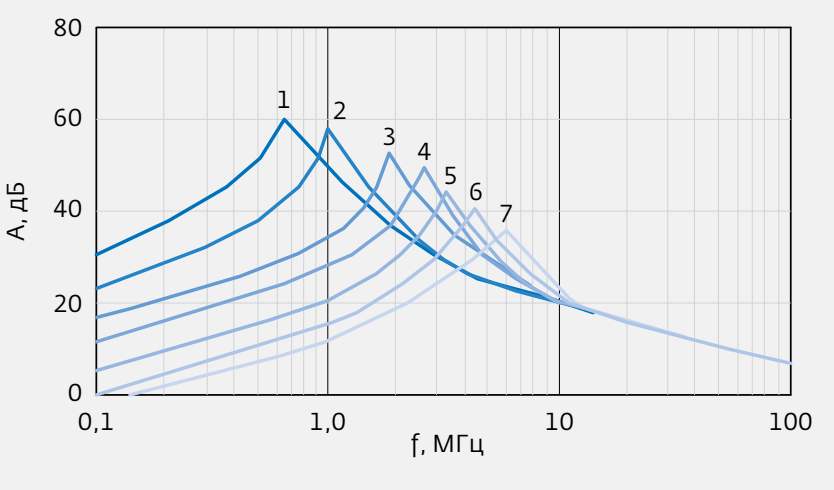

Рис.2. АЧХ конденсаторов К73-57; зависимости: 1- 4,7 мкФ; 2- 2,2 мкФ; 3 - 1,0 мкФ; 4- 0,47 мкФ; 5- 0,22 мКФ; 6-0,1 мКФ; 7-0,047 мКФ 


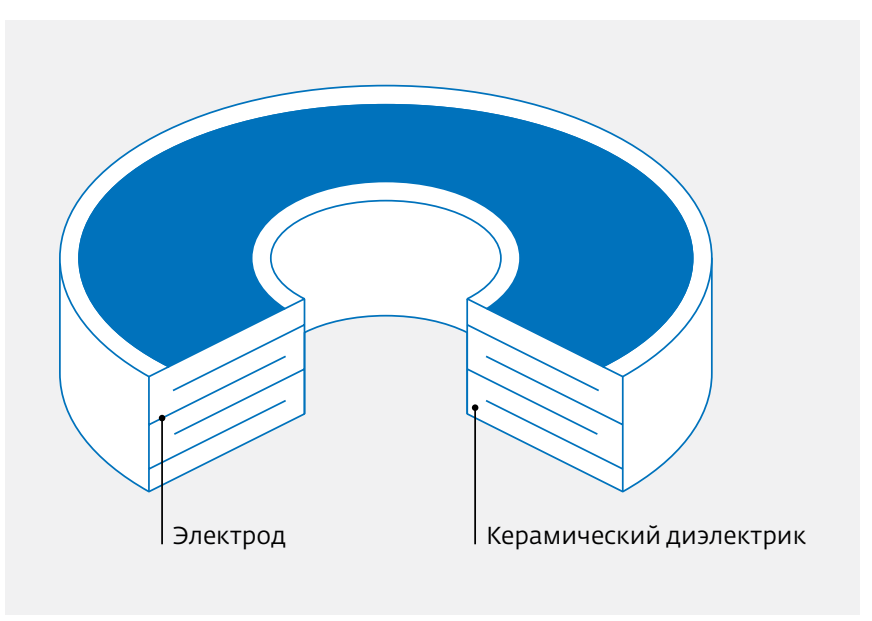

Рис.3. Конструкция шайбовых конденсаторов

ная и удельная емкость таких конденсаторов по сравнению с однослойными увеличилась в тысячи раз. Наибольшее распространение получили конденсаторы для поверхностного монтажа, имеющие форму параллелепипеда (чип-конденсаторы). Такие устройства могут применяться и как блокировочные, например конденсаторы К10-67в-500 В-0,022 мкФ размером 5,7× 5,0 ×3,0 мм в цепях с источниками вторичного электропитания. Спустя время появились помехоподавляющие шайбовые конденсаторы (рис.3).

Таблица 2. Шкала номинальных емкостей конденсаторов К10-85

\begin{tabular}{|c|c|c|c|}
\hline \multirow{3}{*}{$\mathrm{U}_{\text {ном }}, \mathrm{B}$} & \multicolumn{3}{|c|}{ Группа ТСЕ } \\
\hline & МПО & $\mathrm{H} 20$ & $\mathrm{H} 50$ \\
\hline & \multicolumn{3}{|c|}{$\mathrm{C}_{\text {ном }}$} \\
\hline 250 & 4,7-470 пФ & 680 пФ - 0,01 мкФ & 0,$01 ; 0,015$ мкФ \\
\hline \multirow{4}{*}{500} & 470-680 пФ & 3300 пФ-0,033 мкФ & 0,$033 ; 0,047$ мкФ \\
\hline & 1000 пФ & 0,$047 ; 0,068 \mathrm{мк} \Phi$ & 0,068; 0,1 мкФ \\
\hline & $1500 ; 2200$ пФ & 0,$1 ; 0,15 \mathrm{мк} \Phi$ & 0,$15 ; 0,22 \mathrm{м} \mathrm{к} \Phi$ \\
\hline & $3300 ; 4700$ пФ & 0,22 мкФ & 0,33 мк $\Phi$ \\
\hline \multirow{4}{*}{750} & 47-330 пФ & - & - \\
\hline & 470-1000 пФ & - & - \\
\hline & $1500 \Pi \Phi$ & - & - \\
\hline & 2200 пФ & - & - \\
\hline \multirow{3}{*}{1000} & $100-220$ пФ & - & - \\
\hline & $330 \Pi \Phi$ & - & - \\
\hline & 470 пФ & - & - \\
\hline
\end{tabular}

Таблица 1. Основные размеры конденсаторов К10-85

\begin{tabular}{|c|c|c|c|c|}
\hline $\mathrm{S}_{\max }$ & $\mathrm{D}_{\max }$ & $\mathrm{L}_{\max }$ & $\mathrm{D}_{1 \max }$ & $\begin{array}{c}\text { Масса, } \Gamma, \\
\text { не более }\end{array}$ \\
\cline { 1 - 2 } 12,0 & 13,8 & & 9,5 & 5,5 \\
\hline \multirow{2}{*}{14,0} & \multirow{2}{*}{16,4} & 12,0 & 11,5 & 7,0 \\
\cline { 5 - 5 } & & & 13,5 & 7,5 \\
\cline { 5 - 5 } & & 14,0 & & 9,0 \\
\hline
\end{tabular}

Чередующиеся слои керамического диэлектрика и электродов конденсаторов, отдельные слои которых соединены параллельно, образуют емкость между внутренней и внешней контактными поверхностями. Благодаря данной конструкции можно получать значения емкости от единиц пикофарад до нескольких десятков микрофарад [1]. В иностранных каталогах [2, 3] такие конденсаторы называют в основном Multilayer Discoidal Capacitors, а в отдельных источниках отечественной технической литературы - "дискоидальными". В соответствии с конструкцией мы называем такие конденсаторы шайбовыми. Устройства применяются как самостоятельные помехоподавляющие элементы, так и в составе фильтров низкой частоты [4]. Коаксиальная конструкция и параллельное соединение внутренних электродов обеспечивают минимальные значения собственной индуктивности и максимальную частоту собственного резонанса.

\section{МАЛОИНДУКТИВНЫЕ ОПОРНЫЕ КОНДЕНСАТОРЫ К10-85}

Конструкция конденсаторов. Малоиндуктивные опорные конденсаторы К10-85 (рис.4) были разработаны с использованием преимуществ шайбовых конденсаторов. Устройства номинальным напряжением 250, 500, 750 и 1000 В, их корпуса выполнены из латуни с покрытием серебром. Корпус с резьбой служит опорным выводом. Конструкции и основные размеры конденсаторов приведены в табл.1 и на рис. 5, 6. Типоразмеры, группы температурной стабильности (ТСЕ) и номинальные емкости представлены в табл.2. Материалы группы ТСЕ Н90 для конденсаторов 


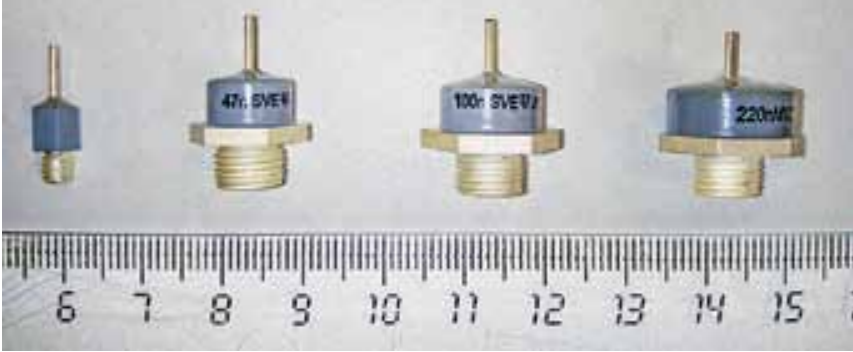

Рис.4. Внешний вид конденсаторов К10-85

не использовались из-за высокой их нестабильности при воздействии температуры и рабочего напряжения.

Параметры помехоподавления. Вносимое затухание конденсаторов А в диапазоне частот от 0,3 до 1300 МГц определялось с помощью измерителей комплексных коэффициентов передач "Обзор-103" и в диапазоне частот от 0,3 до 3200 МГц - "Обзор-304". Эти приборы предназначены для измерения комплексных S-параметров, из которых вносимому затуханию соответствует коэффициент передачи $S_{21}$. АЧХ вносимого затухания конденсаторов с минимальным и максимальным значениями номинальной емкости приведены на рис.7 и 8.

Частота среза АЧХ, при которой вносимое затухание А равняется 3 дБ, точно соответствует соотношению:

$$
F_{c}=1 / \pi R C,
$$

где $\mathrm{F}_{\mathrm{c}}$ - частота среза, Гц;

$\mathrm{R}$ - сопротивление измерительной системы, 50 Ом;

C-емкость конденсатора, $\Phi$.

Значения $F_{c}$ составляют от 20 кГц для емкости 0,33 мкФ и до 900 МГц для емкости 4,7 пФ. На частотах до резонансной частоты вносимое затухание увели-

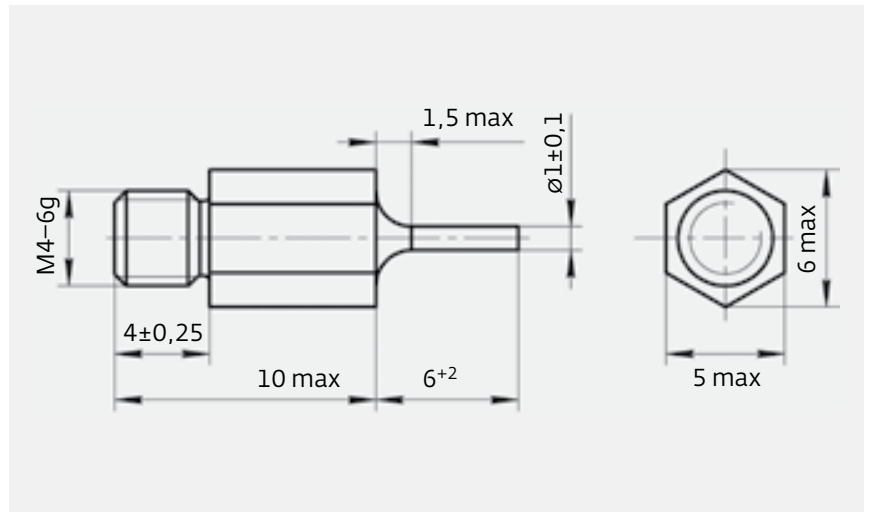

Рис.5. Конструкция и размеры конденсаторов с номинальным напряжением 250 B чивается (крутизна около 20 дБ/декаду). Значения $\mathrm{f}_{\text {рез }}$ находятся в пределах от 4,4 до 1150 МГц. После резонансной частоты вносимое затухание начинает уменьшаться с такой же крутизной - около 20 дБ/декаду. При этом минимальные значения вносимого затухания составляют 8-12 дБ на частоте 1,4 ГГц. На более высокой частоте вносимое затухание увеличивается до 20 дБ. Таким образом, полоса помехоподавления по сравнению с конденсаторами к73-57 (до 20 МГц) была существенно расширена.

На основании измеренных Ачх были рассчитаны значения эквивалентного последовательного сопротивления $\mathrm{R}_{\text {эпс }}$ и собственной индуктивности ( $L=3,5-4,5$ нГн). Значения $L$ изменяются на 0,2-0,3 нГн/мм в зависимости от расстояния до подключения вывода конденсаторов. Значения резонансной частоты и вносимого затухания в технических условиях представлены в табл.3. Так как фактические значения емкости конденсаторов отличаются от их номинального значения в пределах допустимого отклонения, изменяются и значения резонансных частот. Поэтому значения резонансной частоты $\mathrm{f}_{\text {рез }}$ были пересчитаны для номинального значения емкости по формуле:

$$
\mathrm{f}_{\text {рез }}=\mathrm{f}_{\text {рез.изм. }} \sqrt{\frac{\mathrm{C}_{\phi}}{\mathrm{C}_{\text {ном }}}},
$$

где $\mathrm{f}_{\text {рез.изм. }}$ - измеренное значение резонансной частоты,

$\mathrm{C}_{\phi}$ - фактическое значение емкости,

$\mathrm{C}_{\text {ном }}$ - номинальное значение емкости.

Формула справедлива, так как собственная индуктивность конкретного измеренного конденсатора оставалась постоянной. Вместе с указанием резонансной частоты $f_{\text {рез }}$ в табл.3 приводятся значения вносимого затухания на этой частоте.

Для проверки возможного расширения полосы помехоподавления было опробовано параллельное соеди-

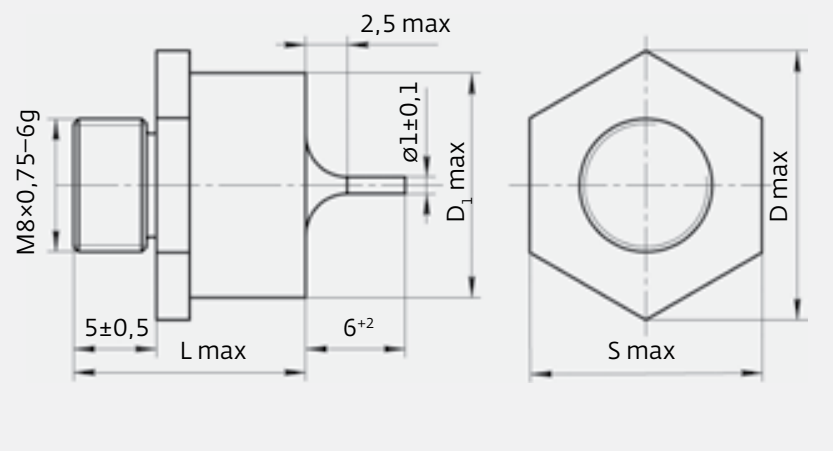

Рис.6. Конструкция и размеры (см. табл.1) конденсаторов с номинальным напряжением 500, 750 и 1000 В 
Таблица 3. Резонансная частота и вносимое затухание конденсаторов К10-85

\begin{tabular}{|c|c|c|c|c|c|c|c|c|c|c|}
\hline \multirow{2}{*}{$\mathrm{C}_{\text {ном }}$} & \multirow{2}{*}{$\begin{array}{l}\mathrm{f}_{\mathrm{pe3}}, \\
\text { МГц }\end{array}$} & \multirow{2}{*}{$\begin{array}{c}A_{\text {рез, }} \\
\text { дБ }\end{array}$} & \multicolumn{8}{|c|}{ Вносимое затухание А, дБ, на частоте $f$, МГц } \\
\hline & & & 0,3 & 1 & 5 & 10 & 50 & 100 & 500 & 1000 \\
\hline 4,7 пФ & 1100 & \multirow{4}{*}{30} & - & - & - & - & - & - & 3 & 30 \\
\hline $6,8 п \Phi$ & 850 & & - & - & - & - & - & - & 4 & 25 \\
\hline 10,0 пФ & 680 & & - & - & - & - & 3 & 10 & 25 & 15 \\
\hline 15,0 пФ & 560 & & - & - & - & - & 5 & 15 & 28 & 14 \\
\hline 22,0 пФ & 460 & \multirow{4}{*}{35} & - & - & - & - & 7 & 20 & 33 & 12 \\
\hline 33,0 пФ & 420 & & - & - & - & - & 3 & 15 & 30 & \multirow{6}{*}{10} \\
\hline 47,0 пФ & 370 & & - & - & - & - & - & 3 & 25 & \\
\hline 68,0 пФ & 290 & & - & - & - & - & - & 3 & 20 & \\
\hline 100,0 пФ & 240 & \multirow{4}{*}{40} & - & - & - & - & - & 5 & 20 & \\
\hline 150,0 пФ & 200 & & - & - & - & - & 3 & 10 & 26 & \\
\hline 220,0 пФ & 155 & & - & - & - & - & 7 & 16 & 10 & \\
\hline 330,0 пФ & 125 & & - & - & - & - & 10 & 35 & 15 & \multirow{11}{*}{8} \\
\hline 470,0 пФ & 110 & \multirow{10}{*}{45} & - & - & - & 3 & 15 & 45 & \multirow{6}{*}{12} & \\
\hline 680,0 пФ & 92 & & - & - & - & 5 & 20 & 45 & & \\
\hline 1000 пФ & 82 & & - & - & - & 10 & 20 & 43 & & \\
\hline 1500 пФ & 69 & & - & - & - & 15 & 25 & 35 & & \\
\hline $2200 \Pi \Phi$ & 58 & & - & - & 3 & 20 & 45 & 30 & & \\
\hline 3300 пФ & 44 & & - & - & 5 & 18 & 43 & 28 & & \\
\hline 4700 пФ & 36 & & - & - & 10 & 12 & 35 & 22 & \multirow{4}{*}{10} & \\
\hline 6800 ПФ & 30 & & - & - & 13 & 15 & 25 & \multirow{3}{*}{20} & & \\
\hline $0,01 \mathrm{M} \Phi$ & 23 & & - & 3 & 14 & 18 & 28 & & & \\
\hline $0,015 \mathrm{M} \Phi$ & 19 & & - & 3 & 15 & 20 & 25 & & & \\
\hline 0,022 мк $\Phi$ & 15 & \multirow{4}{*}{50} & 0,5 & 10 & 30 & 35 & & \multirow{8}{*}{20} & \multirow{8}{*}{10} & \multirow{8}{*}{8} \\
\hline 0,033 мкФ & 13 & & 2 & 13 & 32 & 48 & & & & \\
\hline 0,047 мкФ & 10,5 & & 5 & 18 & 35 & 50 & & & & \\
\hline $0,068 \mathrm{M} \Phi$ & 8,4 & & 9 & 22 & 35 & 48 & & & & \\
\hline $0,1 \mathrm{M} \Phi$ & 6,5 & \multirow{2}{*}{55} & 14,5 & 25 & 41 & 44 & \multirow{4}{*}{20} & & & \\
\hline 0,15 мкФ & 6,2 & & 16 & 30 & 48 & 43 & & & & \\
\hline 0,22 мкФ & 5,5 & \multirow{2}{*}{60} & 19 & 20 & 55 & \multirow{2}{*}{35} & & & & \\
\hline 0,33 мкФ & 4,4 & & 22 & 32 & 58 & & & & & \\
\hline
\end{tabular}


Таблица 4. Допустимые реактивные параметры конденсаторов К10-85

\begin{tabular}{|l|c|c|c|c|}
\hline \multirow{2}{*}{$\mathrm{U}_{\text {ном }}, \mathrm{B}$} & Типоразмер & $\mathrm{P}_{\text {доп, }}, \mathrm{Bap}(\mathrm{H} 20, \mathrm{H} 50)$ & $\mathrm{I}_{\text {доп }}, \mathrm{A}(\mathrm{M \Pi 0})$ & $\mathrm{f}_{0}$ \\
\hline 250 & - & 1,0 & 0,2 & $0,0065 / \mathrm{C}$ \\
\hline \multirow{3}{*}{$500,750,1000$} & 1 & 2,0 & 0,4 & $0,015 / \mathrm{C}$ \\
\cline { 2 - 5 } & 2 & 2,5 & 0,6 & $0,025 / \mathrm{C}$ \\
\cline { 2 - 5 } & 3 & 3,0 & 0,8 & $0,035 / \mathrm{C}$ \\
\hline
\end{tabular}

нение двух опорных конденсаторов - разной емкости, с разнесенными частотами собственного резонанса. АЧХ параллельно соединенных конденсаторов К10-85 номинальной емкостью 0,33 мкФ и 150 пФ приведена на рис.9.

Предполагалось, что конденсатор большей емкости и с меньшей частотой собственного резонанса обеспечит низкое значение полного сопротивления Z в низкочастотной области. И наоборот, конденсатор меньшей емкости и с большей частотой собственного резонанса - низкое значение Z в высокочастотной области требуемого помехоподавления.
Однако предположение подтвердилось не полностью. Конденсатор емкостью 0,33 мкФ находится в индуктивной области, параллельно подключенный конденсатор емкостью 150 пФ-в емкостной. У образовавшегося таким образом колебательного контура на параллельном резонансе с частотой 104,9 МГц резко увеличилось полное сопротивление Z, что отразилось на АЧХ вносимого затухания (см. рис.9). Такое соединение опорных конденсаторов разной емкости может применяться при формировании полосы помехоподавления с заданной АЧХ.

Результат эксперимента был проверен расчетным путем: определена частота резонанса параллельного соединения конденсаторов с помощью формул (4) и (5). 


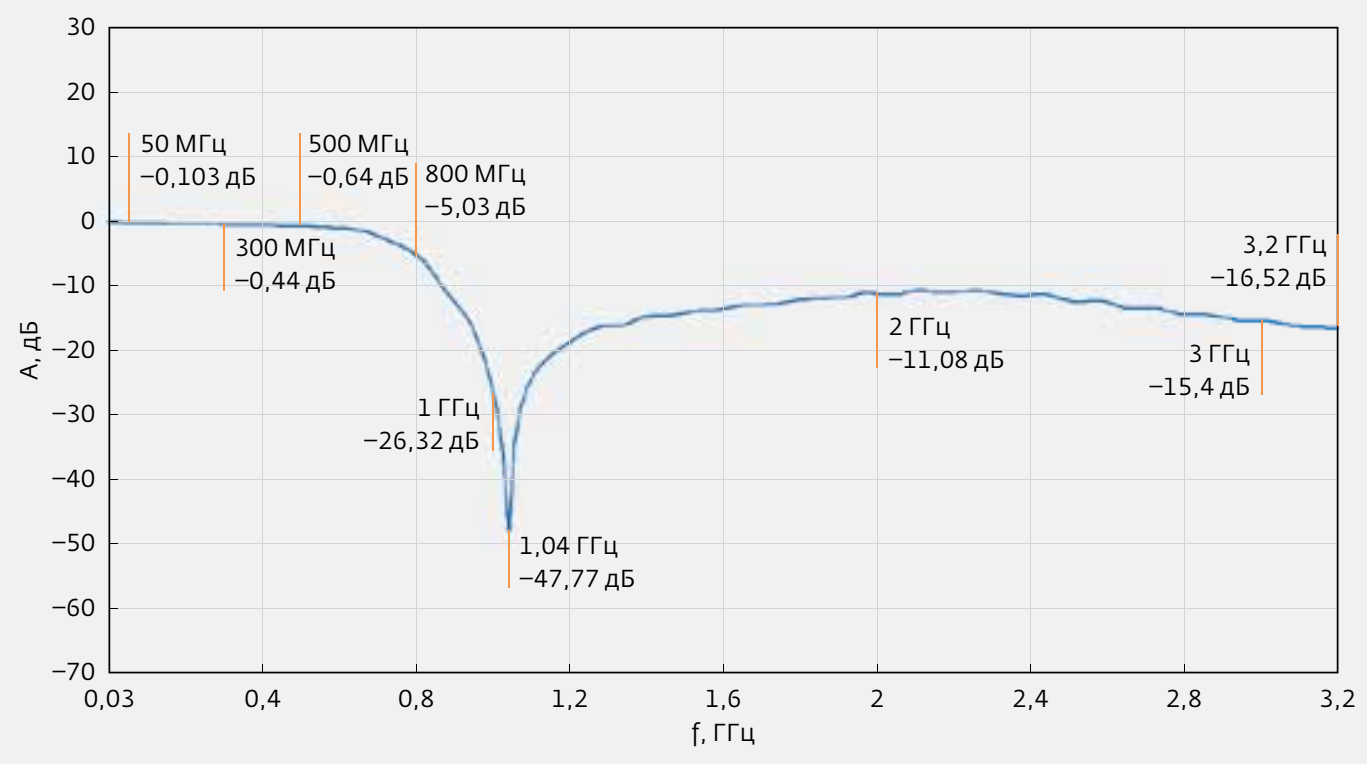

Рис.7. АЧХ конденсаторов К10-85, МП0, 4,7 пФ, 250 B

Результаты АЧХ (см. рис.9) и рассчитанные по формуле (5) практически совпали.

$$
|Z|=\frac{\left|Z_{1}\right|\left|Z_{2}\right|}{\left|Z_{1}\right|+\left|Z_{2}\right|}
$$

$$
\begin{gathered}
f_{\text {peз }}=\frac{1}{2 \pi \sqrt{\left(L_{1}+L_{2}\right)\left(\frac{C_{1} C_{2}}{C_{1}+C_{2}}\right)}}= \\
=\frac{1}{2 \pi \sqrt{(6,36 \mathrm{H} \Gamma \mathrm{H}+7,78 \mathrm{H} \Gamma \mathrm{H})\left(\frac{0,296 \mathrm{MK} \Phi \cdot 134 \Pi \Phi}{0,296 \mathrm{MK} \Phi+134 \Pi \Phi}\right)}}=115,69 \mathrm{MГц,} \mathrm{(5)}
\end{gathered}
$$

где $|\mathrm{Z}|$ - комплексное сопротивление параллельного соединения конденсаторов;

$\left|Z_{1}\right| n\left|Z_{2}\right|$ - комплексные сопротивления первого и второго конденсаторов соответственно.

где $L_{1}$ и $L_{2}$ - фактические индуктивности первого и второго конденсаторов соответственно,

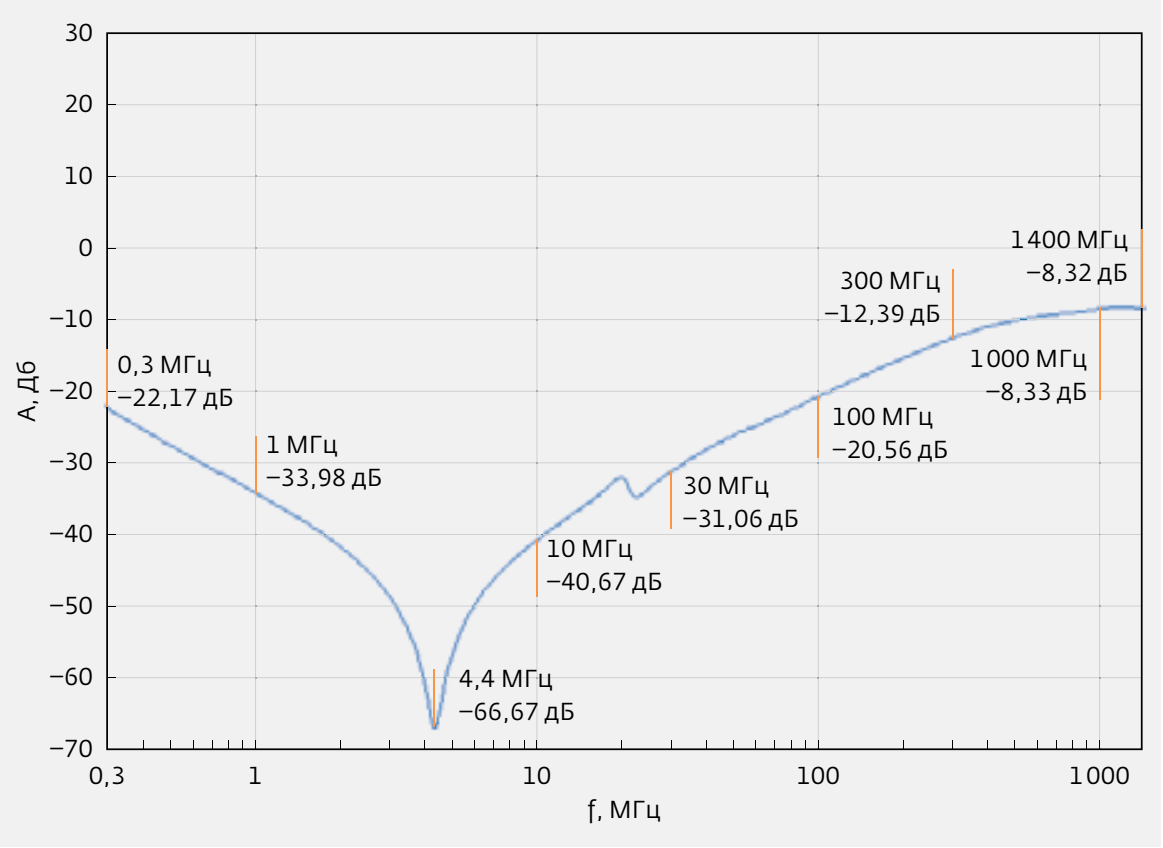

Рис.8. АЧХ конденсаторов К10-85, Н50, 0,33 мкФ, 250 В
$\mathrm{C}_{1}$ и $\mathrm{C}_{2}$ - фактические емкости первого и второго конденсаторов соответственно.

Допустимые реактивные параметры. Предельно допустимые значения реактивных параметров в режимах переменного напряжения необходимы для определения допустимого рабочего переменного напряжения $\mathrm{U}_{\text {раб. }}$. При этих значениях $\cup_{\text {раб }}$ температура поверхности конденсаторов не должна превышать температуру окружающей среды более чем на $5^{\circ} \mathrm{C}$, а параметры конденсаторадолжны оставаться в пределах нормы. Для определения этих параметров температура корпуса конденсаторов измерялась в различных режимах нагрузки переменным током на частотах от 300 Гц до 200 кГц. Керамический диэлектрик группы МПО имеет низкие диэлектрические потери $(\operatorname{tg} \delta=0,0001-$ 
Рис.9. АЧХ параллельно соединенных конденсаторов 150 пФ и 0,33 мкФ

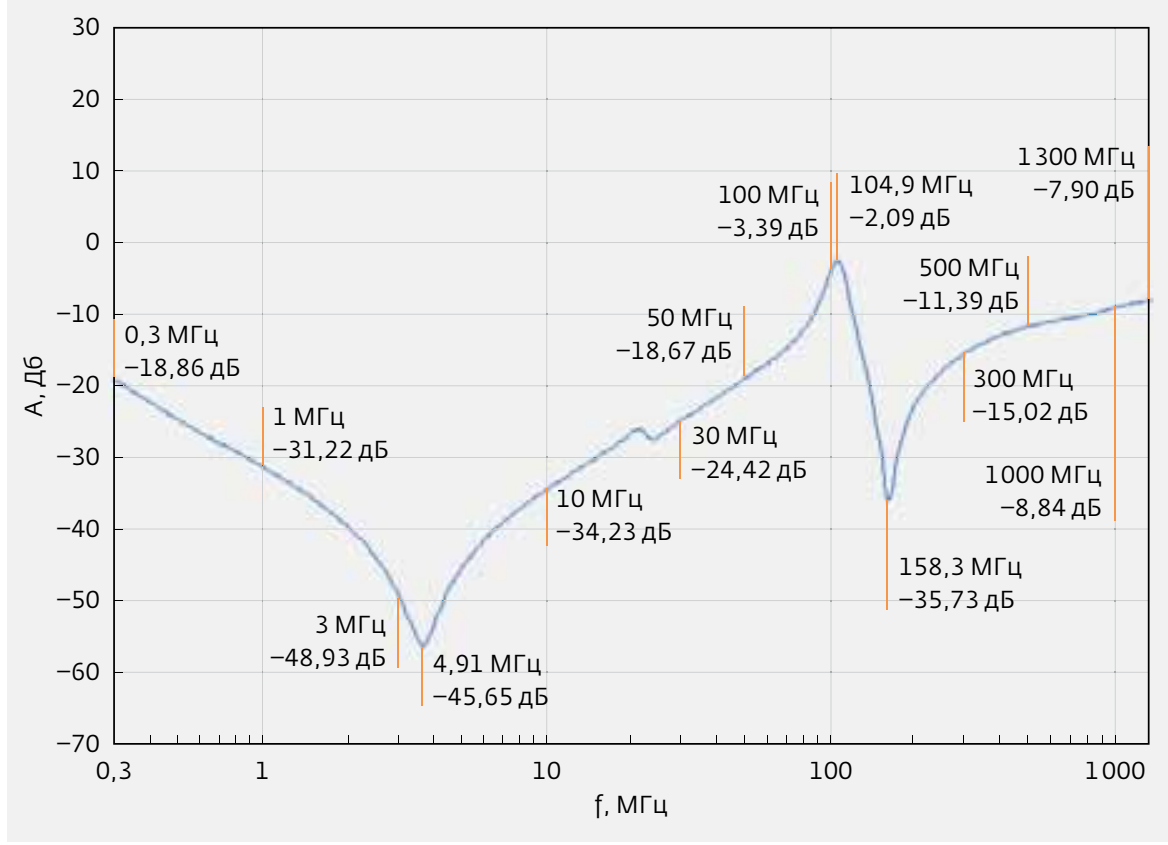

реактивных мощности итока, а также формула для расчета $\mathrm{f}_{0}$ при разных значениях емкости С (табл.4).

$$
\because * *
$$

Новые керамические опорные помехоподавляющие конденсаторы, разработанные в АО "НИИ "Гириконд", удовлетворяют основным требованиям обеспечения помехоустойчивости радиоэлектронных устройств, отличаются низкими значениями собственной индуктивности, для них характерна широкая линейка напряжений и емкостей.

\section{ЛИТЕРАТУРА}

1. Красильщиков М., Смирнов В., шалаева А. Новые керамические помехоподавляющие конденсаторы // Компоненты и технологии. 2010. № 7. C. 60-63.

2. Ceramic capacitors. Каталог фирмы Eurofarad. Франция.

0,001), и конденсаторы этой группы ТСЕ нагревались только за счет нагрева реактивным током Ір металлических частей конденсатора. Нагрев конденсаторов групп H20, Н50 происходит за счет диэлектрических потерь $(\operatorname{tg} \delta=0,005-0,02)$ при реактивной мощности $P_{p}$. Однако на определенной частоте $\mathrm{f}_{0}$ потери в металле сравниваются с потерями в диэлектрике, а при более высоких частотах - превосходят их. Поэтому на частотах $>\mathrm{f}_{0}$ допустимые значения $\mathrm{P}_{\mathrm{p}}$ и $\mathrm{I}_{\mathrm{p}}$ необходимо снижать пропорционально отношению $f / f_{0}$. На основании анализа полученных данных определены предельно допустимые значения
3. Discoidal capacitors. Каталог фирмы Syfer. Англия.

4. Красильщиков М., Смирнов В., Шалаева А. Керамические проходные фильтры нижних частот с малыми потерями // ЭЛЕКТРОНИКА: Наука, Технология, Бизнес. 2009. № 7. С. 28-32, № 8. С. 22-26.

5. Патент на полезную модель № 158534. Керамический опорный помехоподавляющий конденсатор. Авторы: Смирнов В.Ф., Шалаева А.А., Кузьмичев 3.В. Приоритет полезной модели от 23 июня 2015 года.

6. Конденсаторы керамические помехоподавляющие К10-85, технические условия АДПК.673511.019 ТУ. 